Wright State University

CORE Scholar

Physics Faculty Publications

Physics

$7-2016$

\title{
Non-traditional Students' Conceptual Scores and Network Centrality in SCALE-UP Classrooms
}

\author{
Emily N. Sandt \\ Wright State University - Main Campus, sandt.2@wright.edu \\ Adrienne L. Traxler \\ Wright State University - Main Campus, adrienne.traxler@wright.edu
}

Follow this and additional works at: https://corescholar.libraries.wright.edu/physics

Part of the Physics Commons, and the Scholarship of Teaching and Learning Commons

\section{Repository Citation}

Sandt, E., \& Traxler, A. (2016, July 20-21). Non-traditional students' conceptual scores and network centrality in SCALE-UP classrooms. Paper presented at Physics Education Research Conference 2016, Sacramento, CA. Retrieved January 23, 2018, from https://www.compadre.org/Repository/document/ ServeFile.cfm?ID=14252\&DocID $=4606$

This Conference Proceeding is brought to you for free and open access by the Physics at CORE Scholar. It has been accepted for inclusion in Physics Faculty Publications by an authorized administrator of CORE Scholar. For more information, please contact library-corescholar@wright.edu. 


\title{
Non-traditional students' conceptual scores and network centrality in SCALE-UP classrooms
}

\author{
Emily Sandt, and Adrienne Traxler \\ Department of Physics, Wright State University, 3640 Colonel Glenn Highway, Dayton, OH, 45435
}

\begin{abstract}
As classrooms transition from traditional to cooperative learning environments, questions about the details of these environments effectiveness are posed. Does this model equally benefit all students? How do nontraditional (NT) students' gains in conceptual knowledge compare to those of traditional (Trad) students in these classrooms? Do NT students' social differences (i.e. age, employment status, family life, etc.) affect the amount of learning they do in the course or their tendency to form collaborative ties with other students? In three sections of SCALE-UP introductory calculus-based physics, we collected social network survey data about student connections and used the Force Concept Inventory as a pre- and post-course conceptual knowledge diagnostic. Several centrality measures were calculated for the networks and NT and Trad student data were compared to look for significant differences between the two groups' results. We found that NT students are connected to fewer peers but are closer to the inner workings of the network in larger courses.
\end{abstract}

\section{INTRODUCTION}

Interactions between students in the classroom can be integral in enhancing their educational experience, particularly in interactive classrooms such as SCALE-UP classes [1, 2]. These interactions can be quantified and visualized using social network analysis (SNA) to provide large-scale data for classes of various sizes without placing undue burdens, such as time-consuming interviews, on researchers and student subjects. Insight into these interactions will advance understanding of how to create a classroom environment that encourages students to make connections and become more involved in the classroom network. Network involvement has been linked to the feeling of being a part of a learning community, which is pivotal in retaining students $[3,4]$. This is especially important for non-traditional students, who make up a large portion of the student body at Wright State University and many other educational institutions. Implications of this research may be vital as retention of non-traditional students has been related to the feeling of belonging to a community [4] and community integration has been linked to centrality.

Network position has also been linked to measures of student success, such as conceptual gains or grades. For example, Bruun and Brewe [5] found that more inclusion and importance, or centrality, in the network was linked to higher course grades. Various measures of centrality exist. This paper will focus on degree, betweenness, and closeness [6] (defined in Section II), which are common centrality measures that provide different insights into network structure. Brewe et al. [7] also found that classes utilizing interactive engagement (IE) techniques showed a more connected post-course network than that of traditional lectures.

Little work in physics education research (PER) has been done to see if or how non-traditional students (over age 22 for this study) fare differently than traditional students. This paper will look for trends between non-traditional and traditional students' scores on the FCI for pre- and post-course administrations, FCI score gains, and measures of network centrality for three SCALE-UP classes of varying sizes.

\section{METHODS}

\section{A. Context and Data Collection}

Wright State University offers a rare demographic of largely non-traditional (over the age of 22) students. The University is a large public institution with roughly 14,000 undergraduates. Over half of those students are considered non-traditional by the University's definition of age > 22 [8].

Data for this study comes from three sections of a SCALEUP format calculus-based general physics I course. Each section was taught by the same instructor using similar class materials and met three times a week with a built-in recitation section. A one credit (two in-class hours) laboratory was held separately. The course instructor used peer cooperation and cooperative group problem solving combined with lecturing. Dataset A was a summer section with a small class size ( $\sim 30$ students) and one graduate teaching assistant (GTA). Dataset B was a fall section with a moderate class size $(\sim 70$ students) and two GTAs and two undergraduate learning assistants (ULAs). Results from Dataset B are presented in this paper as it shows some of the dynamics of a large dataset, but at a reasonable number of students for reader understanding. Dataset $\mathrm{C}$ was a spring section with a large class size $(\sim 120$ students) and one GTA and five ULAs.

During the first and last weeks of the course, two surveys were given. One was the Force Concept Inventory (FCI) [9], which was administered during class. The other was an online survey which collected network data about the class by providing students with a class roster and asking them to mark any students they "...work with to learn physics in this class." Table I provides the numbers of enrolled students, numbers of non-traditional (NT) and traditional (Trad) students, and response rates for each dataset's pre- and post-course surveys.

\section{B. Data Analysis}

Collected FCI data was scored and score gains were calculated (by subtracting the pre- from the post-course score) for 
TABLE I: Full class and subsetted enrollment values and response rates. (Number of students identified in network survey is larger than the number of survey respondents.)

\begin{tabular}{|c|c|c|c|c|c|c|}
\hline \multirow[b]{2}{*}{ Dataset } & \multicolumn{3}{|c|}{ Pre } & \multicolumn{3}{|c|}{ Post } \\
\hline & Enrolled & FCI & Network & Enrolled & FCI & Network \\
\hline $\mathrm{A}$ & 36 & $69 \%$ & $67 \%$ & 29 & $59 \%$ & $72 \%$ \\
\hline$n_{N T}$ & & 8 & 10 & & 6 & 8 \\
\hline$n_{\text {Trad }}$ & & 17 & 18 & & 11 & 21 \\
\hline $\mathrm{B}$ & 70 & $80 \%$ & $86 \%$ & 71 & $63 \%$ & $61 \%$ \\
\hline$n_{N T}$ & & 15 & 18 & & 9 & 17 \\
\hline$n_{\text {Trad }}$ & & 41 & 51 & & 36 & 46 \\
\hline $\mathrm{C}$ & 125 & $85 \%$ & $80 \%$ & 124 & $74 \%$ & $69 \%$ \\
\hline$n_{N T}$ & & 8 & 11 & & 7 & 8 \\
\hline$n_{\text {Trad }}$ & & 97 & 107 & & 98 & 98 \\
\hline
\end{tabular}

those students with both scores available. Mean and standard error of the mean values for FCI scores and each centrality type were calculated for each subset of students (traditional and non-traditional). The subsets' values were compared using t-tests.

Using $R$ [10], an open source statistical software, the data from the network survey was used to create pre- and postcourse network objects composed of nodes, which represent students who were named in the network, and edges, which are listed connections as study partners between two nodes [11]. Edges were undirected (meaning any connection between two students was treated identically no matter who named who or how often the pair was identified) for simplification of the network. Basic descriptors of a network are the number of nodes, number of edges, and network density. Network density is defined as the total number of edges divided by the maximum number of edges possible: $n(n-1) / 2$, where $n$ is the number of nodes.

\section{Centrality Measures}

Network centrality is a measure of importance of a node's position. Alternatively, centrality attempts to answer the question: How would the network be changed if that node was removed? Three common measures were analyzed: degree, betweenness, and closeness [6]. Degree centrality is simply the sum of connections for a given node or how many peers the student works with. Betweenness centrality is a measure of how often node $i$ is on the shortest path $\left(d_{j k}(i)\right)$ between nodes $j$ and $k$. It describes how often information passes through a student to get to another student in the class and is calculated using Eq. 1.

$$
C_{B}(i)=\sum_{j<k}^{n} \frac{d_{j k}(i) / d_{j k}}{\frac{1}{2}(n-1)(n-2)}
$$

TABLE II: Network survey information for all datasets.

\begin{tabular}{c|ccc|ccc}
\hline \hline & \multicolumn{3}{|c|}{ Pre } & \multicolumn{3}{c}{ Post } \\
Dataset & Nodes & Edges & Density & Nodes & Edges & Density \\
\hline A & 28 & 29 & 0.077 & 29 & 47 & 0.116 \\
B & 69 & 69 & 0.029 & 63 & 70 & 0.036 \\
C & 118 & 203 & 0.029 & 106 & 169 & 0.030 \\
\hline \hline
\end{tabular}

Closeness centrality is calculated using Eq. 2 and describes how "close" node $i$ is to the inner workings of the network by calculating the distance $\left(d_{i j}\right)$ from node $i$ to all other nodes $j$ in the network. Nodes with low closeness centrality are on the outskirts of the network.

$$
C_{C}(i)=\left[\frac{\sum_{j=1}^{n} d_{i j}}{n-1}\right]^{-1}
$$

Degree values are reported between 0 and $n$. The betweenness and closeness definitions used here are normalized to a range between 0 and 1 .

\section{RESULTS}

Table II lists the number of nodes, edges, and network densities for the three datasets. Dataset A became more dense, indicating a more connected class, and Dataset $\mathrm{C}$ became effectively less dense, indicating a less connected class, for the number of nodes in the network by the end of the course. (Smaller networks tend to have higher densities, because the number of possible edges scales as $n^{2}$.) Figure 1 shows a sample visualization of the class network demonstrating Dataset B's density increase.

Table III lists the basic statistics for the FCI scores and centrality measures for each subset of students. Bolded pairs of results show a statistically significant, $p<0.05$, difference between non-traditional and traditional students. FCI gain values were found for those nodes with pre- and post-course scores. Comparing FCI scores at pre- and post-course times reveals conflicting trends with NT students sometimes having higher scores than Trad students and vice versa, but a significant advantage is seen in Dataset $\mathrm{C}$ for non-traditional students. Because the classes have a high degree of instructional similarity, this is likely due to the low $n$ value of NT students.

Across all three data sets, NT students enter the course with lower average centrality values in almost all cases. Though these differences rarely reach a level of statistical significance, this was an expected result. NT students likely are more independent and know fewer peers at the start of the course. The post-course data shows the advantage of examining multiple centrality measures. NT students always have lower degree centrality, but at times have comparable betweenness or closeness centrality. Figure 2 shows the cumulative centrality plot for pre- and post-course degree and 
TABLE III: Mean (and standard error) values for non-traditional (NT) and traditional (Trad) students in all datasets with FCI gains for students with pre- and post-course FCI scores.

\begin{tabular}{cc|cccc|cccc|c}
\hline \hline & & \multicolumn{3}{|c|}{ Pre } & & & Post & & Gain \\
Dataset & Subset & FCI & Degree & Betweenness & Closeness & FCI & Degree & Betweenness & Closeness & FCI \\
\hline \multirow{2}{*}{ A } & NT & $9.8(0.9)$ & $1.9(0.4)$ & $0.04(0.02)$ & $0.08(0.01)$ & $12(2)$ & $2.3(0.8)$ & $0.02(0.02)$ & $0.15(0.02)$ & $-0.5(3)$ \\
& Trad & $7.5(0.8)$ & $2.1(0.4)$ & $0.06(0.02)$ & $0.087(0.006)$ & $13(2)$ & $3.6(0.5)$ & $0.06(0.02)$ & $0.180(0.008)$ & $5(1)$ \\
& NT & $12(2)$ & $1.6(0.3)$ & $0.02(0.01)$ & $0.025(0.002)$ & $\mathbf{1 2 ( 1 )}$ & $1.8(0.3)$ & $0.06(0.03)$ & $0.073(0.007)$ & $5(3)$ \\
B & Trad & $12(1)$ & $2.1(0.2)$ & $0.029(0.008)$ & $0.06(0.02)$ & $\mathbf{1 5 ( 1 )}$ & $2.4(0.3)$ & $0.06(0.02)$ & $0.077(0.003)$ & $4(1)$ \\
& NT & $9(2)$ & $2.6(0.9)$ & $0.02(0.02)$ & $0.044(0.007)$ & $17(3)$ & $\mathbf{1 . 5 ( 0 . 5 )}$ & $\mathbf{0 . 0 0 6}(\mathbf{0 . 0 0 3})$ & $0.035(0.006)$ & $\mathbf{7 ( 2 )}$ \\
C & Trad & $12.2(0.6)$ & $3.5(0.3)$ & $0.019(0.002)$ & $0.052(0.001)$ & $14.5(0.8)$ & $\mathbf{3 . 3 ( 0 . 3 )}$ & $\mathbf{0 . 0 2 2}(\mathbf{0 . 0 0 3})$ & $0.037(0.001)$ & $\mathbf{2 . 5 ( 0 . 6 )}$ \\
\hline \hline
\end{tabular}

closeness centrality values of NT and Trad students in Dataset B. The degree plot does not show much change from preto post-course; NT students remain with lower degree values and neither subset shows substantial degree centrality gain. This implies that the network did not change much throughout the course, however the closeness plot shows that the network did change with NT students beginning with lower and ending with comparable closeness to that of Trad students.

\section{DISCUSSION}

Dataset B's results are intriguing as NT students have fewer study partners, but nearly identical closeness and betweenness values. In other words, NT students have fewer connections, but are connected in some way that gives them equal access to network resources. The network diagrams for this data (Fig. 1) show fewer isolated nodes in the post-course compared to the pre-course network.

Dataset $\mathrm{C}$ is interesting as it is the largest SCALE-UP section analyzed and shows a decline in all (except Trad betweenness) centrality values with a lower effective network density at the end of the semester, meaning the nodes rearranged themselves to be more isolated in the post-course network. This was not seen in Datasets A or B, where centrality values typically grew and the networks became more dense.

The low numbers of NT students and low class sizes in Datasets A and B make it difficult to discern statistically significant differences between NT and Trad students' centrality or FCI outcomes. However, some patterns are seen which might be further investigated through qualitative work. NT students begin the course with lower closeness values and, with the exception of Dataset A, end the course with comparable closeness values. They also always have lower degree centrality than Trad students do. This suggests that although the IE technique is meant to facilitate student interactions, NT students are not interacting with their peers in the same way as Trad students.

A particularly interesting result is found in the FCI gain values. As the class size increases, NT students appear to learn more, while Trad students obtain less conceptual knowledge. This may or may not be a statistically significant result of the shift in secondary education to more IE techniques in class sizes comparable to that of Dataset A.
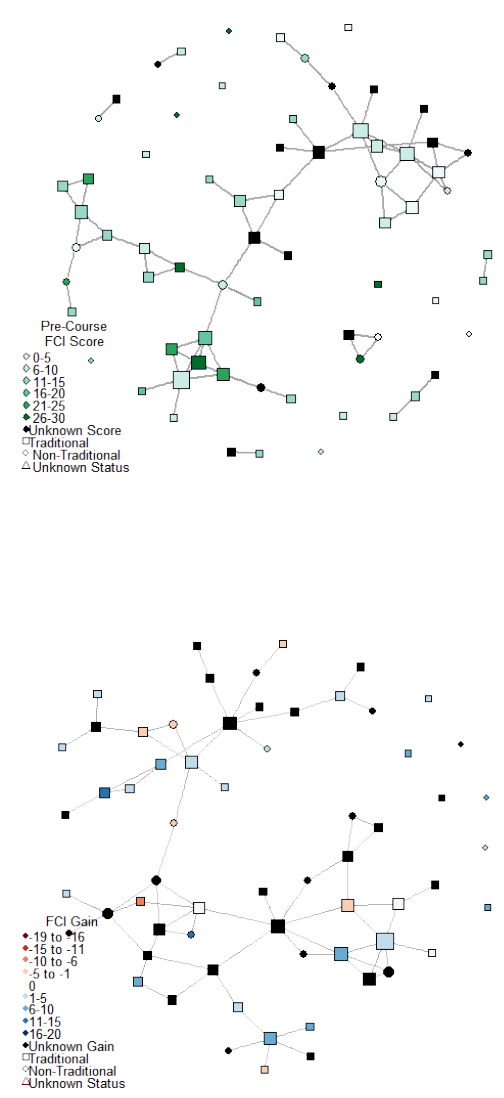

FIG. 1: Pre- (top) and post-course (bottom) network diagrams for Dataset B. Nodes are colored by FCI score pre-score or gain, sized by degree centrality values and shaped by designation as traditional or non-traditional. 


\section{CONCLUSIONS}
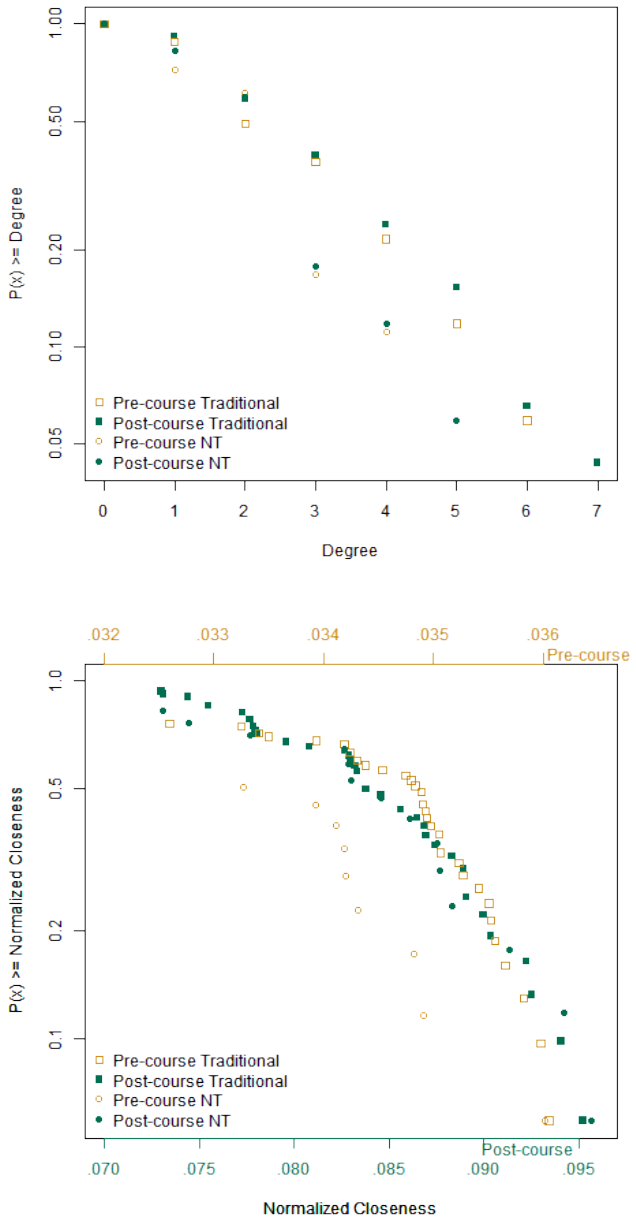

FIG. 2: Cumulative centrality plots for degree (top) and closeness (bottom) of Dataset B show the fraction of students with a centrality value equal to or above the $\mathrm{X}$-axis value. Degree shows a similar growth for both student types, while closeness shows that NT students gained more closeness than Trad students to end at comparable values.
This study revealed that non-traditional students show different trends in network centrality than those of traditional students. Non-traditional students consistently have fewer connections, but make connections that keep them closer to the network's inner-workings, particularly in large classes.

As the class size increased, a trend was revealed of nontraditional students having higher gains in conceptual knowledge, while traditional students have smaller gains in conceptual knowledge. This indicates that the effectiveness of IE in the classroom is still affected by class size.

Evidence has been shown to support the use of multiple measures of network centrality. Using one centrality measure does not provide the whole picture of a network's structure and can be misleading if analyzing network dynamics from pre- to post-course.

Future work will continue to survey a range of class sizes to see if these trends are the norm. This analysis could be extended to see if non-traditional students tend to network among themselves or with traditional students. Additionally, correlations between centrality and conceptual measures (which appear in some cases of the preliminary results) should be explored in detail.

\section{ACKNOWLEDGMENTS}

Wright State University's Graduate Council awarded Emily Sandt a Wright Fellowship for the 2014-2015 school year.
[1] R. J. Beichner, J. M. Saul, D. S. Abbott, J. J. Morse, D. L. Deardorff, R. J. Allain, S. W. Bonham, M. H. Dancy, and J. S. Risley, in Research-Based Reform of University Physics, edited by E. F. Redish and P. J. Cooney (American Association of Physics Teachers, 2007), vol. 1 of Reviews in PER.

[2] S. Freeman, S. L. Eddy, M. McDonough, M. K. Smith, N. Okoroafor, H. Jordt, and M. P. Wenderoth, Proceedings of the National Academy of Sciences of the United States of America 111, 8410 (2014).

[3] S. Dawson, Educational Technology \& Society 11, 224 (2008).

[4] V. Tinto, The Journal of Higher Education 68, 599 (1997).

[5] J. Bruun and E. Brewe, Physical Review Special Topics Physics Education Research 9, 1 (2013).

[6] L. C. Freeman, Social Networks 1, 215 (1979).
[7] E. Brewe, L. H. Kramer, and G. E. O’Brien, AIP Conference Proceedings 1289, 85 (2010).

[8] Transfer and N. S. Center, Nontraditional Students at Wright State (2016), URL https:// www.wright.edu/transfer/orientation/ nontraditional-students-at-wright-state.

[9] D. Hestenes, M. Wells, and G. Swackhamer, The Physics Teacher 30, 141 (1992).

[10] R Development Core Team, R: A Language and Environment for Statistical Computing, R Foundation for Statistical Computing, Vienna, Austria (2008), URL http://www. R-project.org.

[11] I. McCulloh, H. Armstrong, and A. Johnson, Social Network Analysis with Applications (John Wiley \& Sons, 2013). 